\title{
FLER HUVUDEN VÄNTAS FALLA
}

\section{METAFOR OCH METONYMI I SVENSKA SOMATISMER MED LEXEMET HUVUD}

\author{
EWA WALATEK
}

Jagiellonian University in Kraków

ABSTRACT. The purpose of this study is to give a detailed analysis of the semantics of the Swedish body part term huvud (head). The study covers all types of linguistic units including the component huvud (idioms, compounds), both conventionalized everyday expressions and occasional uses. The theoretical basis of the analysis is the cognitive theory of metaphor and metonymy formulated by Lakoff and Johnson (1980).

A large part of semantic extensions of huvud are associated with the head as the upper part of the human body, containing the brain and sense organs. These features lead to metonymies: HEAD FOR THINKING ABILITY AND PERCEPTION and metaphor HEAD IS POSITION OF COMMAND. The head itself is conceptualized metaphorically as a CONTAINER in which thoughts, memories, emotional and physical states are stored.

\section{INLEDNING}

Syftet med föreliggande artikel är att analysera de semantiska strukturer som lexemet huvud utvecklar. Ordet är högfrekvent (Niemi 2002:249f.) och ingår i ett stort antal uttryck som syftar på diverse erfarenhetssfärer (till exempel livet, personerna, tankeförmågan $\mathrm{m} \mathrm{m}$ ). Den semantiska analysen omfattar inte endast den utomspråkliga motiveringen till ordets betydelser utan först och främst de metaforiska och metonymiska processer som ligger till grund för användningen av ordet huvud i olika kontexter.

I mina analyser har jag använt mig av allmänna svenska ordböcker: Illustrerad svensk ordbok (ISOB), Nordstedts svenska ordbok (NSOB), 
Nationalencyklopedins ordbok (NEO), Svenska Akademiens ordbok (SAOB), Svensk ordbok (SO) samt en fraseologisk ordbok Svenskt språkbruk (SB).

Jag har även analyserat exempel från den svenska textkorpusen Parole (K). Korpusens textmaterial har insamlats av Institutionen för svenska språket vid Göteborgs universitet och den är tillgänglig på nätet (www.spraakbanken.gu.se/parole).

Förutom de ovannämnda källorna har jag även använt mig av sökmotorn Google (G). En viktig fördel både med korpusen och med sökmotorn är att de ger tillgång till ett stilistiskt varierat material.

I artikelns teoretiska del sammanfattas kort tidigare forskning som genomförts kring metafor och metonymi inom den kognitiva lingvistiken. Båda företeelserna betraktas som begreppsmekanismer som strukturerar människans tänkande (Lakoff \& Johnson 1980). Den praktiska delen består av en presentation av metaforer och metonymier som har haft del i uppkomsten av svenska somatismer med lexemet huvud.

\section{DEN KOGNITIVA METAFORTEORIN}

Begreppet metafor kommer från grekiskan och betyder att något överförs från ett ställe till ett annat (Johannesson 1990:152). Metaforteorier har långa anor men de bygger alla i stort sett på uppfattningen om metaforen som ett lingvistiskt fenomen som baserar på likheter mellan två entiteter och som används som litterärt och retoriskt verktyg vid förfinat språkbruk. Under de senaste decennierna har metaforen satts i fokus i språkforskningen. Vändpunkten utgjordes av boken Metaphors we live by av Lakoff \& Johnson (1980) som bildade underlag för den kognitiva lingvistikens syn på metaforens betydelse.

Lakoff \& Johnsson (1980) hävdar bland annat att metaforen inte tillhör ordens utan snarare begreppens och tankarnas värld, att metaforens huvudsyfte är att göra det lättare att förstå vissa begrepp, att metaforen inte enbart är baserad på likhet, att alla använder sig av metaforen till och med i de vardagliga situationerna och slutligen att det är våra tankar och handlingar som ligger till grund för metaforer (Kövecses 2002:viii).

\subsection{KONCEPTUELL METAFOR}

Enligt den kognitiva lingvistiken innebär termen metafor att man uppfattar en domän i term av en annan domän (Kövecses 2002:4). Vi tänker exempelvis på livet med hjälp av termer som kommer från domänen resa, på diskussioner i termer av strid, på teorier i termer av byggnader $\mathrm{m} \mathrm{m}$. Konceptuella metaforer går således ut på en konceptuell sammanlänkning av så kallade käll- och måldomäner. Källdomänen är en domän som används för 
att göra det lättare att begripa måldomänen. Därför utgörs källdomänen vanligtvis av företeelser som upplevs vara mer konkreta och fysiska än måldomänen som i sin tur oftast är ett abstrakt fenomen.

Med tanke på vilken kognitiv funktion metaforer uppfyller delas de in i tre kategorier: strukturella, orienterande och ontologiska (Kövecses 2002:32f.).

Strukturella metaforer går ut på att man strukturerar en domän i termer av en annan domän. Vi uppfattar exempelvis diskussion som en strid och använder oss därför av ord och uttryck som har en tydlig koppling till stridens erfarenhetssfär, som t ex försvara, angripa samt träffa mitt $i$ prick (Lakoff \& Johnson 1980:4f.).

I orienterande metaforer utnyttjar vi vår uppfattning av rumsliga förhållanden som vi känner till från den konkreta verkligheten/världen. Vår fysiska erfarenhet ligger till grund för följande konceptualiseringar (Jakobsson 1996:9, jfr Kövecses 2002:35f.):

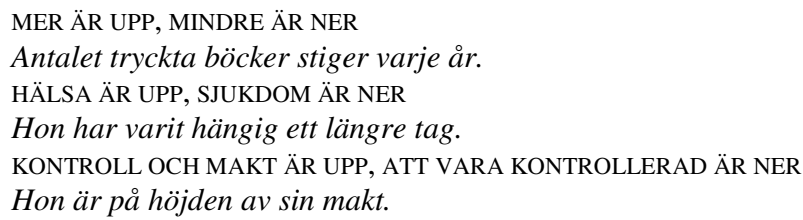

Ontologiska metaforer går ut på att vi i våra tankar gör abstrakta begrepp till avgränsade och gripbara entiteter som objekt, substanser och behållare, vilket i stor utsträckning underlättar att hänvisa till dem, kvantifiera dem och att ställa dem i relation till varandra (Lakoff \& Johnson 1980:25ff.). Som exempel på ontologiska metaforer kan man nämna: HJÄRNAN/SJÄLEN (THE MIND) ÄR EN MASKIN (Kövecses 2002:35). I svenskan hittar vi en del uttryck som bygger på den metaforen:

Hon har nog inte kopplat riktigt.

Jag känner mig lite rostig.

\subsection{FÖRESTÄLLNINGSSCHEMAN}

Föreställningsscheman (image schemas) hänger samman med att vårt tänkande och vårt språk är starkt präglade av våra grundläggande fysiska erfarenheter. Människan har en erfarenhet av kroppen som en tredimensionell behållare, $\mathrm{d} v \mathrm{~s}$ en erfarenhet av att röra sig i en rumslig dimension, av att komma i kontakt med andra, och av att använda sig av olika verktyg. Dessa kroppsliga erfarenheter påverkar i stor utsträckning vårt tänkesätt och 
motiverar följaktligen även metaforer (Lakoff 1987:444-447 efter Jakobsson 1996:10).

Bland de vanligaste schemana kan nämnas: BEHÅLLARE, BLOCKERING, VÄG, HELHET - DEL, LÄNK, UPPREPNING, YTA, BALANS, SKALA, AVSTÅND, CENTRUM - PERIFERI, KRAFT (Johnson 1987:126 efter Strzelecka 2003:39).

\subsection{METONYMI}

Termen metonymi kommer från grekiskan och betyder namnbyte. Den innebär att ett ord eller ett uttryck ersätts med ett annat, varvid det finns en naturlig koppling mellan dem, $\mathrm{t}$ ex en förbindelse i tid och rum (Strzelecka 2003:45). Enligt den kognitiva lingvistiken utgör metonymi en mycket viktig del av vårt språkbruk. Metonymi uttrycker i likhet med metafor vissa återkommande mönster i vårt tänkande (Lakoff \& Johnsson 1980:39f.).

Metonymiernas roll är att göra vårt språk ekonomiskt genom att lyfta fram det som är mest betydelsefullt i en konkret situation. När man säger att det behövs nya hjärnor i ett projekt eller starka ben i ett fotbollslag utpekar man samtidigt vilka personegenskaper som är mest relevanta i sammanhanget (Porwisz 2004:80).

Traditionellt uppfattades huvudskillnaden mellan metafor och metonymi ligga $i$ att en metafor mappar två begrepp som kommer från två skilda domäner medan metonymiska mappningar äger rum mellan två begrepp inom samma domän (Lakoff 1987:288). Croft (1993:340f.) påpekar att ett begrepp till och med kan stå i samband med flera olika domäner; bakgrunden till begreppet människa utgörs exempelvis av följande domäner: fysiska objekt, levande varelse, känslor $\mathrm{m} \mathrm{m}$.

\section{ANALYS AV LEXEMET HUVUD}

En av de mest grundläggande betydelser som ordet huvud har och som anges av de svenska ordböckerna (SO, SAOB, NEO, NSOB ISOB) är "avslutande, översta eller främsta del av kroppen (på människa eller djur), där centra för de viktigaste sinnesorganen samt hjärnan är placerade". Denna innebörd syftar först och främst på huvudets placering och dess betydelse för tanke- och förnimmelseprocesser. De flesta uttryck med ordet huvud utgör en utvidgning av denna definition. 


\subsection{ORDET HUVUD I METONYMISKA ANVÄNDNINGAR}

\subsubsection{HUVUDET FÖR LIVET}

Huvudet är utan tvekan en av de viktigaste delarna i vår kropp som man inte kan leva utan. Historiskt sett var det ett vanligt straff för grova brott att avrätta förövaren genom halshuggning. Även om man har frångått denna typ av straff, har man i fraseologin bevarat kunskapen om avrättning genom halshuggning. Den utgör bas för en talrik grupp av fraseologismer som presenteras nedan.

(1) bli ett huvud kortare (SB)

(2) det kommer att kosta honom huvudet (SAOB)

(3) det gäller huvudet (SAOB)

(4) $[\ldots]$ riskera ära och huvud $(\mathrm{K})$

Berövande av huvudet står i ovannämnda exempel som metonymi för berövande av livet. I uttrycken nedan är det däremot en metafor för hård bestraffning (ex 5,6) eller avsättning från ledande poster $(e x 7,8)$.

(5) begära/kräva någons huvud på ett fat (SB)

(6) Labi sade att det är Sali Berishas huvud demonstranterna är ute efter [...] (K)

(7) $[\ldots]$ redaktörers och universitetsrektorers huvuden har rullat $[\ldots](\mathrm{K})$

(8) $[\ldots]$ hans chefer är redan avstängda, och fler huvuden väntas falla [...] (K)

\subsubsection{HUVUDET FÖR PERSONEN}

I vissa fraser som representerar metonymin DELEN FÖR HELHETEN, $\mathrm{d}$ v s pars pro toto står huvudet för människan.

(9) från huvud till huvud (SAOB)

(10) Vi äter, sa han vänligt till huvudena som stack opp ovanför strättorna [...] (K)

(11) $[\ldots]$ där hade krönta huvuden vilat $[\ldots](\mathrm{K})$

\subsubsection{HUVUDET FÖR TANKEFÖRMÅGAN/INTELLEKTET}

Sambandet mellan huvudet och människans intellekt är självklart eftersom hjärnan som styr alla tankeprocesser finns just i huvudet. I många konstruktioner framställs huvudet inte bara som den kroppsdel där det förekommer tankeprocesser utan också som ett slags redskap för tänkande.

(12) Man kan med sitt huvud inse att det är befängt att tro att ens barns sjukdom kommer som straff $(\ldots)(\mathrm{K})$ 
(13) anstränga/bry/bråka sitt huvud eller huvudet (med något) (SAOB)

I nedanstående konstruktioner symboliseras människans tankeförmåga av att hon helt enkelt äger ett huvud.

(14) $[\ldots]$ modern har både utseende och huvud [...] (K)

(15) Det är huvud på killen, sade Henrik [...] (K)

I uttrycket tappa huvudet konceptualiseras huvudet till och med som ett föremål som kan skiljas från kroppen:

(16)En ambassadör kan bli satt ur spel om han inte har en intelligent sekreterare och en chaufför som inte tappar huvudet om det blir folkupplopp och skottlossning. (K)

(17) [...] en karl som tappar huvudet och rusar omkring som en skrämd hare [...] (K)

\subsubsection{HUVUDET SOM BESLUTSCENTRUM}

I vissa fraser framställs familjen metaforiskt som en kropp. Eftersom huvudet är en kroppsdel som på grund av hjärnans placering är ansvarig för tänkandet och därmed utgör en sorts centrum för hela kroppen, representerar ordet huvud i dessa fraser den människa som får bestämma och är mest tongivande i en gemenskap, vilket har sin grund i metonymierna DELEN FÖR HELHETEN och HUVUD FÖR TANKEFÖRMÅGA. Dessa metonymier har otvivelaktigt del i uppkomsten av metaforen CENTRUM ÄR HUVUD som ligger till grund för nedan nämnda exempel.

(18) Mannen är familjens huvud och kvinnan är halsen som får honom att röra sig. (G)

(19) (...) mannens roll som familjens huvud och försörjare. (G)

\subsection{ORDET HUVUD I METAFORISKA SAMMANHANG}

I en talrik grupp metaforer konceptualiseras huvudet som en behållare, $\mathrm{i}$ vilken bland annat människans tankar, begåvningar, emotionella och fysiska tillstånd kan förvaras. Dessa konceptualiseras i sin tur som föremål. En annan grupp av metaforiska uttryck utgörs av fraser i vilka huvudet står för en gräns för människans inflytande, tankeförmåga och möjligheter.

\subsubsection{HUVUDET SOM BEHÅLLARE FÖR FYSISKA OCH MENTALA TILLSTÅND}

I nedanstående exempel åskådliggörs $t$ ex värken som ett föremål som finns i behållaren. 
(20) ha ont i huvudet (SB)

(21) ha ont i skallen (SB)

\subsubsection{HUVUDET SOM BEHÅLLARE FÖR TANKAR}

Eftersom huvudet åskådliggörs som en behållare, implicerar detta att det kan fyllas med ett innehåll. Tankarna kan även infinna sig i behållaren av sig själva utan människans inflytande.

(22) En idé dök upp i hennes huvud. (K)

(23) Men trots att det har gått lång tid så är Ulla inte fri från det som hände:

- Ibland bara kommer det upp i huvudet [...] (K)

Även andra människor kan placera något $\mathrm{i}$ subjektets huvud utan att hen har kontroll över denna process. Detta betyder att andra personer utövar inflytande på ens tänkande.

(24) [...] för det andra är de misstänksamma mot oss därför att de tror vi sätter borgerliga idéer i huvudet på dem $[\ldots](\mathrm{K})$

Ibland finns det endast en tanke i huvudet, vilket implicerar att alla mindre viktiga tankar har försvunnit för tillfället och att subjektet helt och hållet fokuserar på en sak.

(25) Reine hade en enda tanke i huvudet [...] (K)

Subjektet kan till och med få bort tankarna ur huvudet. Då åskådliggörs tankarna som fysiska föremål som kan tas ut ur en behållare. Om subjektet självt avlägsnar innehållet, implicerar detta att hen har bestämt att sluta tänka på något.

(26) Jag kan inte få ur mitt huvud att en bandspole antagligen snurrar under bordet. (K)

(27) slå något ur sitt huvud (SOAB)

Om huvudet beskrivs som en tom behållare innebär det att tankeverksamheten är omöjlig för tillfället.

(28) Jag gick därifrån med tomt huvud och lungor fulla av rök jag inte ville ha. (K)

(29) [...] jag känner mig tom i skallen [...] (G)

(30) Just nu är jag ganska tom i bollen [...] (G) 


\subsubsection{HUVUDET SOM BEHÅLLARE FÖR INFORMATIONER, MINNEN OCH ERFARENHETER}

I likhet med föremål i en behållare kan man förvara erfarenheter, informationer och kunskaper i huvudet. Detta implicerar att man kommer ihåg information eller en händelse, att man kan något eller tänker på något.

(31) $[\ldots]$ tankeschemana finns i människors huvuden [...] (K)

(32) $[\ldots]$ offren finns i mitt huvud [...] (K)

(33) $[\ldots]$ vi bär ordens mening i våra huvuden $[\ldots](\mathrm{K})$

(34) $[\ldots]$ när jag redan har en bild i mitt huvud $[\ldots](\mathrm{K})$

Ibland bevaras vissa minnen i huvudet mot subjektets vilja:

(35) [...] när bilderna från kriget spelas upp i mitt huvud blir jag nästan tokig [...] (K)

\subsubsection{HUVUDET SOM ETT RUM}

De föregående exemplen har även lyft fram att huvudet kan uppfattas som ett rum. I de nedanstående fraserna åskådliggörs tankarna som levande väsen som i olika stora mängder går genom rummet och förmodligen också lämnar det.

(36) Det gick många tankar genom huvudet på sjuksköterskeeleven [...] (K)

(37) $[\ldots]$ tankarna som drar igenom hennes huvud [...] (K)

Människans mentala verksamhet åskådliggörs också såsom aktivitet som subjektet själv utför i behållaren. I detta fall visualiseras huvudet ofta som ett rum som människan kan röra sig i. Att subjektet företar aktiviteterna själv antyder att hen har kontroll över sina tankar.

(38) I huvudet kompletterar han sin slutmening [...] (K)

(39) Han satt tyst en lång stund, vägde orden inne i huvudet [...] (K)

(40) Hon hade försökt att reda ut det i sitt huvud [...] (K)

Nedanstående uttryck åskådliggör huvudet till och med som en slags verkstad som kan innehålla lämplig eller bristande utrustning. Utrustningen står för förmågan att tänka.

(41) vara klent eller väl utrustad å huvudets vägnar (SAOB) 


\subsubsection{TANKEVERKSAMHET ÄR RÖRELSE}

I en stor grupp fraser framställs huvudet som en behållare i vilken tankarna förflyttar sig med en varierande hastighet och på olika sätt, vilket anknyter till metaforen TANKEVERKSAMHET ÄR RÖRELSE. Ju högre hastigheten är desto febrilare tankeverksamhet utövar subjektet.

(42) Tankarna rusade omkring i hans huvud. (K)

(43) [...] det var sådana ord som jagade runt i huvudet på Ellen [...] (K)

(44) Olika fantastiska förklaringar virvlade runt i hennes huvud [...] (K)

Däremot syftar ingen rörelse i behållaren på att tankeverksamheten inte utövas eller är omöjlig för tillfället.

(45) [...] då står det plötsligt alldeles still i huvudet [...] (K)

\subsubsection{OREDA I HUVUDET - KAOS I TANKARNA}

Som antytts ovan, finns det en hel del språkliga belägg i vilka huvudet konceptualiseras som ett rum medan tankarna framställs som objekt som finns eller rör sig i rummet. Om rummet beskrivs såsom rörigt, implicerar detta kaos i tankarna och förvirring.

(46) Gör inte det är du snäll, det blir bara oreda i ditt lilla huvud. (K)

(47) Det var en fruktansvärd oordning i mitt huvud, som i någon annans portfölj. (K)

\subsubsection{HUVUDET SOM GRÄNS FÖR INFLYTANDE, TANKEFÖRMÅGA OCH MÖJLIGHETER}

På grund av att huvudet utgör den översta och avslutande delen av kroppen har det uppstått en del uttryck i vilka huvudet symboliserar en gräns för vårt inflytande. Allt som sker/händer/görs över vårt huvud befinner sig utanför vår kontroll. Dessa uttryck används ofta i politiska sammanhang och betonar medborgarnas maktlöshet inför överhetens beslut. Man kan förbinda deras ursprung med metaforen MAKT ÄR UPP (jfr Lakoff \& Johnson 1980).

(48) Vi fastnar allt mera i känslan av maktlöshet och känner oss tvingade till en anpasslighet till de väldiga krafterna över våra huvud (...) (K)

(49) Vi visste ingenting förr i världen om vad som hände, allt hände över våra huvuden men nu blir vi ju upplysta i alla fall. (K)

(50) Beslutet som tagits över huvudet på partiledaren kan ses som ett direkt resultat av Buttigliones flört med Berlusconi och högern. (K) 
Användningen av verben hänga och sväva i följande två exempel betonar osäkerhet och fara.

(51) $[\ldots]$ jordskredet hänger ovanför våra huvuden [...] (K)

(52) En katastrof hade svävat över hans huvud [...] (K)

I fraserna något går över huvudet på någon samt någon talar över/ovanför huvudet på någon framstår huvudet som en gräns för tankeförmågan.

(53) Vissa frågeställningar går över huvudet på dem [...] (K)

(54) den stolte fadern förklarade poesins väsen över huvudet på sin minderåriga dotter (SB)

I fraserna växa någon över huvudet, ta vatten över huvudet och ha göromål upp över huvudet utgör huvudet en gräns för våra möjligheter och begåvningar. Allt som finns över huvudet blir till en sorts överlastning, börda, krav som inte kan tillgodoses.

(55) Skulderna växer honom över huvudet och livet känns inte längre värt att leva. (K)

(56) Forskningstidskrifterna håller nämligen på att växa sina läsare över huvudet, både i volym och i kostnader. (K)

(57) Unga simmare tog sig vatten över huvudet (...) (G)

\subsection{SAMMANFATTNINGAR}

Det finns en tämligen omfattande grupp sammansättningar med morfemet huvud där detta ord kan utgöra både förled och efterled.

\subsubsection{HUVUD SOM FÖRLED}

Efter en grundläggande analys av dessa sammansättningar kan man konstatera att sammansättningarna med morfemet huvud som förled kan delas in i tre grupper med tanke på vad förleden syftar på.

Den första och talrikaste gruppen består av de sammansättningar i vilka morfemet huvud utgör förled med betydelsen 'ledande eller viktigaste representant för det som efterleden betecknar' (NEO).

Detta kan belysas med ett urval exempel:

(58) På slaget fyra stod jag utanför huvudentrén till sjukhuset och väntade på Andro. (K)

(59) Folkets Teater hade köpt en pjäs som han skrivit förra vintern och engagerat honom själv i huvudrollen $[\ldots](\mathrm{K})$

(60) En hälsning från vår kungliga huvudstad $[\ldots](\mathrm{K})$

(61) Tar du huvudansvaret för Bill då? (K)

(62) Etik, moral och rättvisa är huvudkraven [...] (K) 
I en del exempel på sammansättningar och avledningar syftar förleden på huvud som centrum för förnimmelse - och tankeförmåga. Adjektivet huvudlös betyder följaktligen att något inte har blivit tillräckligt genomtänkt.

(63) Ungdomen sprang snabbt och huvudlöst [...] (K)

(64) Rudolf försökt få dig att övertyga mig om lämpligheten i sina huvudlösa planer [...] (K)

I de nedanstående exemplen presenteras sammansättningar i vilka förleden hänvisar till huvud som en kroppsdel.

(65) Populär historia Käke från en orangutang, tänder från en schimpans och huvudskål från en modern människa [...] (K)

(66) Det är de som regelbundet besöker moskén, och vilkas kvinnor bär huvudduk [...] (K)

\subsubsection{HUVUD SOM EFTERLED}

En mindre grupp bildas av sammansättningar i vilka morfemet huvud utgör efterleden. Efterleden huvud används bland annat vid beteckning av vissa klotformiga grönsaker vilkas form beror på ett stort antal blad som ligger i varv. Denna typ av metafor bottnar i iakttagelsen att huvudet har en rund form.

(67) Kålhuvud som inredningsdetalj? (G)

(68) Stor som ett salladshuvud [...] (G)

Eftersom huvudet utgör den översta delen av kroppen överförs detta även till ett pappersark och dess översta del som följaktligen betecknas som brevhuvud.

De ovannämnda exemplen tydliggör att morfemet huvud som efterled först och främst syftar på huvudets klotformiga form samt på dess placering $\mathrm{i}$ kroppen.

\section{SAMMANFATTNING}

Ordet huvud har utvecklat en mycket rik semantisk struktur. Den realiseras genom talrika metaforiska och metonymiska utvidgningar. Huvudet anses vara en av vår kropps viktigaste delar, vilket ligger till grund för metonymin HUVUDET FÖR LIVET. På grund av hjärnans placering associeras huvudet också med tankeverksamhet. Följaktligen står huvudet i en tämligen omfattande grupp av fraser för tankeförmågan/intellektet. Den sista gruppen uttryck som ingår i de metonymiska utvidgningarna av ordet huvud hänger samman med att huvudet uppfattas som beslutscentrum. 
En annan mycket talrik kategori av somatismer med lexemet huvud består av uttryck i vilka huvudet konceptualiceras som en tredimensionell behållare. I huvudet förvaras följaktligen människans fysiska och mentala tillstånd, tankar, informationer, erfarenheter och minnen.

En tämligen stor grupp av uttryck anknyter till huvudets placering i kroppen. Huvudet kan även ses metaforiskt som gräns för inflytande, tankeförmåga och möjligheter.

Det som framstår är det att synonymer till ordet huvud, $\mathrm{d} v \mathrm{~s}$ boll och skalle först och främst konceptualiseras som behållaren, $\mathrm{t}$ ex få in något $i$ skallen, ha något $i$ skallen, någon är tom $i$ bollen.

Ordet huvud förekommer också i sammansättningar både som förled och som efterled. Som förled har morfemet huvud vanligast betydelsen 'ledande eller viktigaste representant för det som efterleden betecknar' (NEO). Dessutom kan förleden huvud anknyta till tanke - och förnimmelseförmåga eller till själva kroppsdelen. Huvud som efterled används i synnerhet vid beteckningar på vissa klotformiga grönsaker.

Det insamlade materialet har dragit fram den stora semantiska potentialen hos lexemet huvud i ljuset. I figur 1 presenteras en nätverksmodell för dess mest framträdande betydelseutvidgningar. Lexemet huvud är mycket produktivt och de redan existerade betydelserna blir troligen utgångspunkter för ytterligare utvidgningar. 


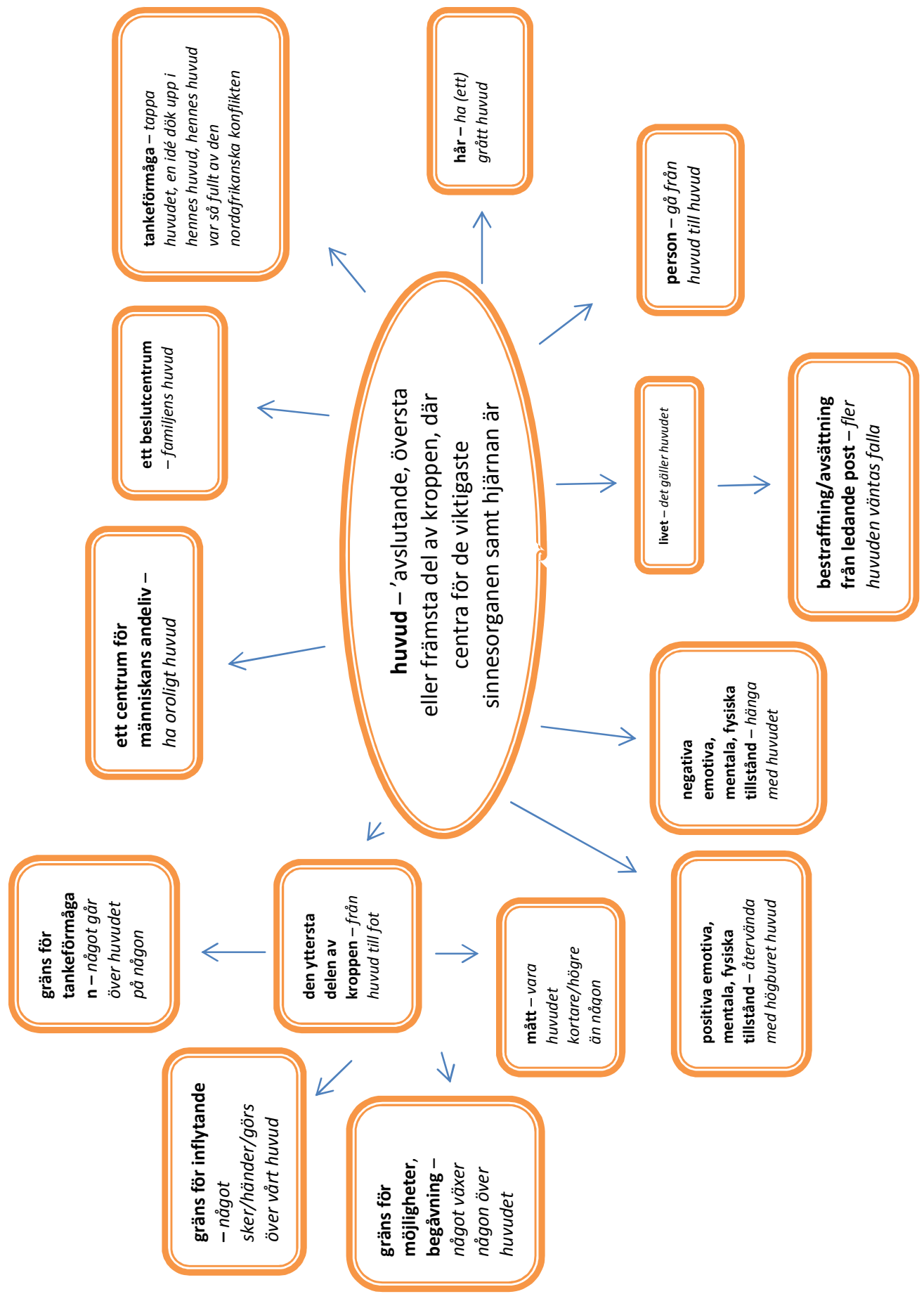

Figur 1. Nätverksmodell för lexemet huvud 


\title{
LITTERATURFÖRTECKNING
}

Croft, William. 1993. The role of domains in the interpretation of metaphors and metonymies. Cognitive Linguistics 4-4, s. 335-370.

Jakobsson, Ulrika. 1996. Familjelika betydelser hos STA, SITTA och LIGGA. En analys ur den kognitiva semantikens perspektiv. Lund: Nordlund 21. Småskrifter från Institutionen för nordiska språk i Lund.

Johannesson, Kurt. 1990. Retorik eller konsten att övertyga. Stockholm: Norstedts förlag AB.

Kövecses, Zoltan. 2002. Metaphor. A Practical Introduction. Oxford - New York: Oxford University Press.

Lakoff, George \& Mark Johnson. 1980. Metaphors We Live By. Chicago: University of Chicago Press.

Lakoff, George. 1987. Women, Fire, and Dangerous Things: What Categories Reveal About the Mind. Chicago: University of Chicago Press

Niemi, Sinikka. 2002. Svenskans kroppsdelsidiom ur ett språktypologiskt perspektiv. I: Melander, Björn et al. (red.). Svenskans beskrivning 26. Förhandlingar vid Tjugosjätte sammankomsten för svenskans beskrivning. Uppsala den $25-26$ oktober 2002. Uppsala: Hallgren \& Fallgren, s. 246-254.

Porwisz, Grażyna. 2004. Metonymi i samspel med metafor. I: Filologiskt smörgåsbord. En jubileumsskrift från skandinavistiken i Kraków. Kraków: WUJ, s. 79-93.

Strzelecka, Elżbieta. 2003. Svenska partikelverb med in, ut, upp och ner. En semantisk studie ur kognitivt perspektiv. Uppsala: Skrifter utgivna av Institutionen för nordiska språk vid Uppsala universitet.

\section{ORDBÖCKER}

Illustrerad svensk ordbok, 1958, andra reviderade upplagan, red. av B. Molde, Natur och Kultur, Stockholm. (ISOB)

Nationalencyklopedins ordbok, 2004, Utarbetad vid Språkdata, Göteborgs universitet, Höganäs. (NEO)

Norstedts svenska ordbok, 2003, red. av Sture Allén, Utarbetad vid Språkdata, Göteborgs universitet, Göteborg. (NSOB)

Svensk ordbok, 1986, Utarbetad vid Språkdata, Göteborgs universitet, Göteborg. (SO)

Svenskt språkbruk. Ordbok över konstruktioner och fraser, 2003, red. av Svenska språknämnden, Svenska språknämnden och Norstedts Ordbok, Göteborg. (SB)

\section{ELEKTRONISKA KÄLLOR}

Google, http://google.se (G) (tillgång 21.04.2011).

PAROLE, http://spraakbanken.gu.se/parole (K) (tillgång 15.03.2011).

Ordbok över svenska språket utgiven av Svenska Akademien, http://g3.spraakdata.gu.se/saob.

(SAOB) (tillgång 22.03.2011).

\author{
Ewa Walatek \\ Uniwersytet Jagielloński \\ Instytut Filologii Germańskiej \\ ul. Straszewskiego 25/2 \\ 31-113 Kraków \\ Poland \\ ewa.walatek@uj.edu.pl
}

